and on 29 December his wish was granted. He died of virus-induced pneumonia. How can this disease be anyone's friend? But this description of bronchopneumonia must have been more typical of the deaths in 1918 than the exaggerated tales of blood and gore. It was bad enough in it quietness, strangulation and breathlessness, and needs no exaggeration.

These post-1918 epidemic waves of flu last until 1922 or so, and then we encounter, albeit briefly, the outbreak of 'sleepy sickness', which immobilized another 5 million souls around the world.

Through page after page we relive that period and can ask ourselves whether it could happen again. Of course it could, and we are no better prepared to resist it. Influenza virologists know this, the World Health Organization knows it and so do publichealth specialists. But still we seem to be suspended as if in a dream, like Alice in Wonderland. There is fine talk of vaccines and antivirals, but if such a pandemic influenza A virus were to jump the species barrier this month, we could all be caught in a catastrophe as serious as that of 1918 .

This book is a wake-up call. It should reach beyond our small, incestuous coterie of a few hundred flu virologists into a far greater world that will not like what it sees. The theme here is that a new virus will come. We have the knowledge and the scientific means to blunt its virulence, but the attention of politicians and decision-makers has been diverted towards bioterrorism and war.

Should this timely book prove a turning point, then we could label Barry as a saviour, although it is clear that this was not his intention when writing the book. He totally immerses us in the 1918 flu battle. These first scientists challenged the natural order, and when the great influenza came they placed their lives in the path of the disease. The scientific knowledge that is still coming out of studies of the 1918 pandemic points us "to much that lies in medicine's future". The ordered, quiet world of Maxwell has vanished. But no amount of slick presentation or clever lawyers' talk from our leaders will escape this volcano sitting in all our countries.

Influenza was the twentieth century's weapon of mass destruction, killing more than the Nazis, more than the atomic bomb, and more than the First World War. We would do well to dwell very seriously indeed on this fact. Nature is the greatest bioterrorist of our world, and we should concentrate and expand our efforts in public health. Emerging viruses could do for us all, as easily and as quickly, or even more so, than the Great Influenza of 1918.

John Oxford is at Retroscreen Virology Limited, Centre for Infectious Diseases, Institute of Cell and Molecular Science, Queen Mary's School of Medicine and Dentistry, University of London, London E1 4NS, UK.

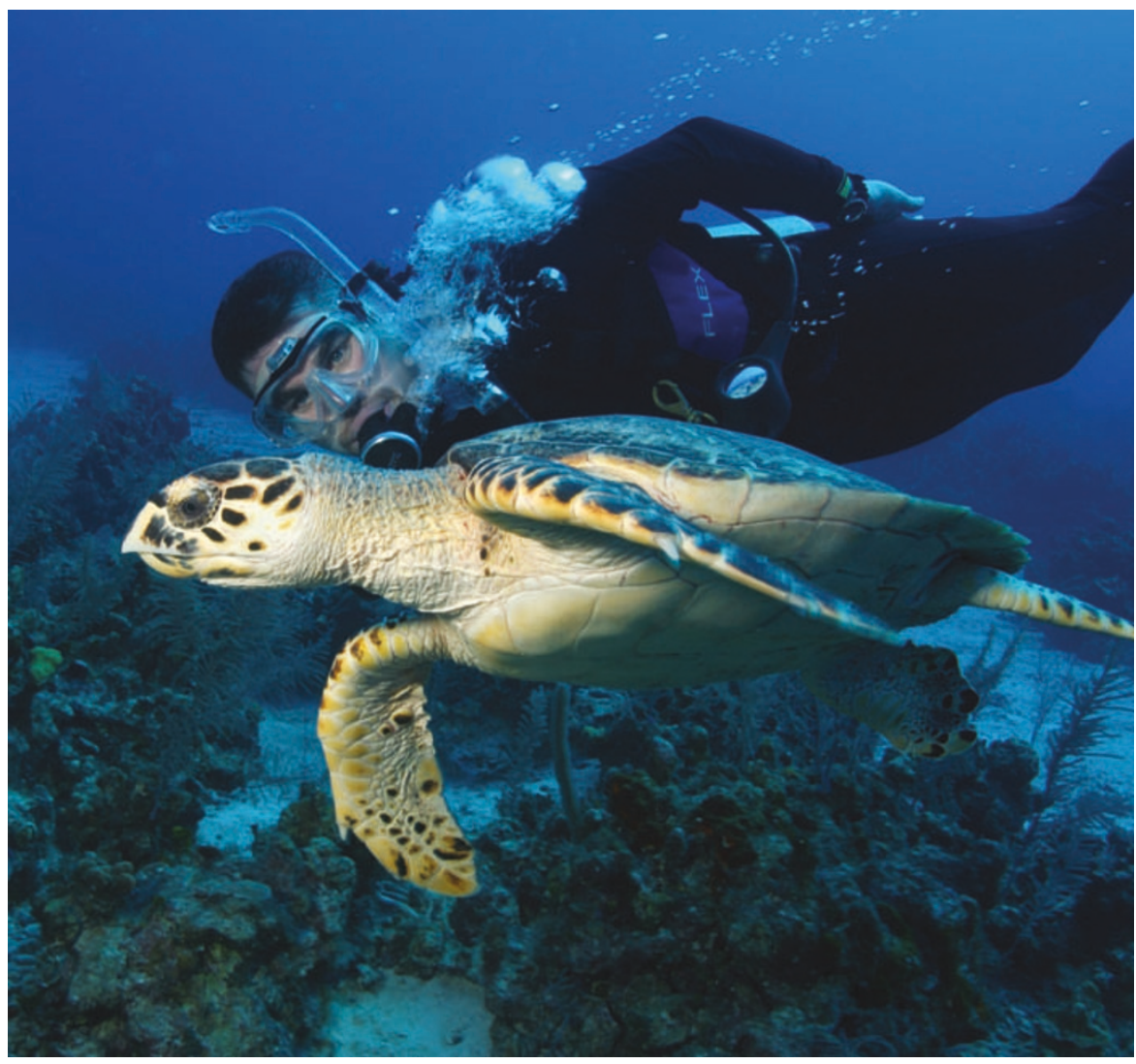

Deep trouble: turtles, once a common sight on Caribbean reefs, have been destroyed by hunting.

\section{Taking stock of conservation}

\section{Against Extinction: The Story of Conservation \\ by William M. Adams \\ Earthscan: 2004. 328 pp. $£ 55$ (hbk),

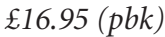

\section{E. J. Milner-Gulland}

I recently observed a UK delegate at a conference lecturing a representative of a developing country's wildlife ministry on how they should be doing conservation. The question under discussion was not the one that might have been asked a few decades ago - "What are you doing for the species?" - but rather, "What are you doing about rural poverty?"

Bill Adams' book Against Extinction encourages us to reflect on the continuities and upheavals in the way we do conservation. As Adams insightfully points out, most conservationists have three time-frames: the long term, for comparing extinction rates, for example; their lifetime, for nostalgia about paradise lost; and the immediate crisis, for most of their interventions. He wants us to look at conservation on another time-frame — the past century - to help us understand the route that led to our current conservation philosophies, and, in so doing, to reflect on our unwitting prejudices and assumptions.
Ignorance of recent history, described by Daniel Pauly as the "shifting baseline syndrome", is a pernicious and prevalent problem in conservation. J. B. C. Jackson has pointed out that current observations of Caribbean reefs are of an ecosystem that has already been fundamentally altered from its natural state by human intervention. Observers in the fifteenth century, before turtle populations were ravaged by hunting, described densities so high that it seemed ships might run aground on them. Jackson memorably described present-day Caribbean reef systems, which have few turtles, as being like the Serengeti without the ungulates. There are many examples in which our ignorance of human and ecological history clouds our understanding of contemporary events. So I applaud Adams' insistence that we look back to obtain a true perspective on the conservation movement today.

Adams' definition of conservation is narrow, and he makes it clear from the start that he is considering only the birth of conservation among Western colonial nations, starting around the middle of the nineteenth century. Central to the book is an organization now called Fauna and Flora International, which celebrated its centenary last year. It has led the way in Western conservation thinking throughout the past century, changing from its origins as an influential group of colonial hunters primarily focusing on game animals in Africa to its current role, working through local, non-governmental 
organizations and concentrating on incountry capacity-building.

I can sympathize with the need to tell a manageable and coherent story, but it is frustrating to have such a narrow view of the roots of conservation perpetuated, particularly by someone who is well aware of this view's limitations. To take just one example, the Mongolians pride themselves on having set up the world's first National Park in 1778 — as do the Americans in 1872. Clearly there are issues surrounding the definition, but it is a shame that the latter view of history is ubiquitously and uncritically repeated in conservation texts.

One of the pleasures of the book is Adams' explanation of the complex intertwining over the past century of the concepts of sustainable use, hunting and wildlife preservation. Some concepts, such as biodiversity and sustainable development, are recent additions; others have shifted in and out of fashion, metamorphosing as they went. Although the early conservationists tended to be exclusionary in their outlook, they were well aware of the potential of sustainable use as a conservation tool. We can be sure that most of the 'new ideas' of conservation were actually reawakened as the dynamic culture of conservation shifted again.

Most of the book is determinedly factual and full of detail, with many interesting examples and case studies - although readers will be hard-pressed to find them again, as the book has no bibliography or visual aids such as chronologies, relying instead on chapter-based endnotes and an inadequate index. The book will also be frustrating for those who wish to find scientifically based analyses of the pros and cons of different conservation approaches; that is not the book's aim. The final chapter, in which Adams outlines his vision for conservation, seems to belong to a different book. The ideas in it are challenging and raise fascinating questions, but seem strangely disengaged from his previous careful historical analysis.

One of the things that makes conservation interesting and challenging is that its practitioners have many perspectives and disciplinary backgrounds. This cultural diversity is growing as social scientists become more fully engaged. One of the great hopes for conservation in the future is this need to look at issues through others' eyes. Just as ecologists now need to be able to perform quantitative analyses, so recently trained conservationists cannot get by without learning social science. This book is a major contribution towards opening conservationists' eyes to another world of historical and cultural understanding, which I welcome wholeheartedly.

E. J. Milner-Gulland is in the Department of

Environmental Science and Technology,

Imperial College London, Exhibition Road,

London SW7 2AZ, UK.

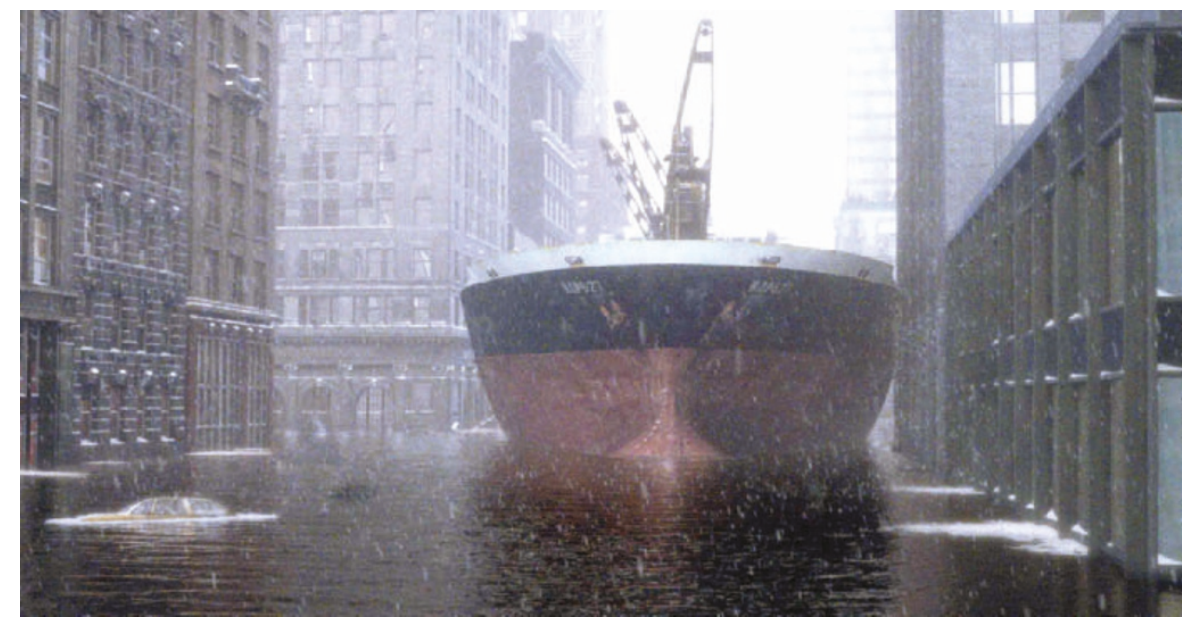

All at sea: climate change is looming over us, but will it really leave New York under water?

Film

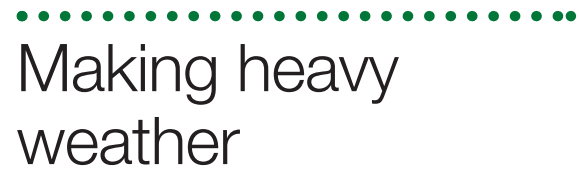

The Day After Tomorrow

Directed by Roland Emmerich

20th Century Fox

Worldwide release on 28 May 2004

\section{Myles Allen}

I have yet to meet a doctor who doesn't dismiss the TV drama ER as hopelessly unrealistic, and yet who doesn't tape it religiously if they happen to be on call. I've also yet to meet a doctor who doesn't regard meteorologists and oceanographers as spotty geeks who couldn't possibly be doing anything glamorous enough to be worth a TV series, never mind a blockbuster Hollywood film. So, with the release of The Day After Tomorrow, a blockbuster-and-a-half inspired by the issue of human-induced sudden climate change, we must be careful not to confirm the medics' worst suspicions by pedantically carping on about the film's portrayal of geophysical fluid dynamics.

A medic watching this film would learn as much about climate as I would learn about cardiology watching ER — not nothing, but I would prefer the surgeon standing over me with a scalpel, or the politician pondering my petrol taxes, to have had some additional training. So I find the fuss about the film's possible impact on climate policy rather disturbing. Bjørn Lomborg vehemently attacked the film recently in the Independent on Sunday for bouncing politicians into signing the Kyoto Protocol. It's a film, lighten up. I'm sure the world's teenagers can work out that this is hardly exam revision material, and if it inspires a few of them to stick with physics for a couple more years and perhaps consider a university course in the geosciences, then it will have more than justified its special-effects budget.

Could The Day After Tomorrow do for meteorology and oceanography what Top Gun did for US Air Force recruitment? The special effects are stunning and the filmmakers have clearly gone to some lengths to base them all on natural phenomena, although the connections between them are more tenuous. A tidal wave could indeed hit New York, albeit one more likely induced by a submarine landslip than a gigantic storm surge. Strange things do happen in the eyes of hurricanes, although to get stratospheric temperatures at sea level you have to be fairly creative with your thermodynamics. I draw the line at someone embedding a hurricane model into a global weather model in 48 hours, but perhaps it is wise not to tell the teenagers what climate modelling actually involves until after they have signed up.

I believe that the public takes a much more sophisticated line than Lomborg fears. I am involved in a public-participation experiment (www.climateprediction.net) that is looking, among other things, at how the atmosphere might reinforce a thermohaline slow-down. Contributions from the public on the discussion boards have generally been level-headed. Everyone understands that there's a link to issues raised by the film without mistaking the film for a forecast.

So, the film is well worth a lab night out, particularly if your model is giving trouble. Perhaps the hardest part will be judging how to respond to questions in the pub afterwards about whether this has anything to do with our actual projections for humaninduced climate change. We have to be clear that the film is science fiction, but we also have to make sure we don't belittle what is actually going on. A prescient dinosaur, gazing future-wards over the millennial undulations of global temperatures, would probably just about make out the warming spike representing our humble contribution to the twenty-first century. It's quite an egoboost, isn't it? The last species to have this much influence on the climate was almost certainly green, slimy and inarticulate. A teenager signing up for the geosciences today 